\title{
MÉTODOS ÁGEIS COMO AUXILIADORES NO GERENCIAMENTO DE PROJETOS
}

\author{
Gustavo Marin Suppi ${ }^{1}$ \\ Rodrigo Ribero ${ }^{2}$ \\ Márcio José Sembay ${ }^{3}$ \\ Igor Muzeka ${ }^{4}$ \\ Juliana Facchini de Souza ${ }^{5}$ \\ Ingrid Solange Sepúlveda Muñoz
}

Resumo: Os métodos ágeis são constituídos de elementos fundamentais para o desenvolvimento de software e gestão de projetos. É frequentemente adotado por milhares de empresas com o intuito de auxiliar melhor a interação da equipe de desenvolvimento e proporcionar apoio na criação do sistema, que vai da concepção até a conclusão do projeto, esses métodos visam melhorar o processo e otimizar o trabalho da equipe. Por meio de uma revisão de literatura, o objetivo foi coletar dados publicados dentro da área de engenharia de software, utilizando métodos ágeis de modo a comprovar sua eficácia dentro dos projetos. Foram utilizados trinta artigos. Por meio deste estudo, conclui-se que o uso das metodologias ágeis pode ser eficiente no desenvolvimento de software e indispensável para uma equipe e para os stakeholders, o que o torna satisfatório, porém, serão necessários mais estudos para comprovar os resultados aqui discutidos.

Palavras-chave: Scrum; Ferramentas para gerir projetos.

\footnotetext{
${ }^{1}$ Ciência da Computação, Centro Universitário Unifacvest, Brasil. E-mail: gustavomarinsuppi@gmail.com.

${ }^{2}$ Ciência da Computação, Centro Universitário Unifacvest, Brasil. E-mail: guigo ribeiro@hotmail.com.

${ }^{3}$ Ciência da Computação, Centro Universitário Unifacvest, Brasil. E-mail: 3m_sembay@yahoo.com.br.

${ }^{4}$ Ciência da Computação, Centro Universitário Unifacvest, Brasil. E-mail: igormzk21@gmail.com.

${ }^{5}$ Ciência da Computação, Centro Universitário Unifacvest, Brasil. E-mail: ju_facchini@hotmail.com.

${ }^{6}$ Ciência da Computação, Centro Universitário Unifacvest, Brasil. E-mail: professoraingrid2009@hotmail.com.
} 